\title{
Níveis de cloreto de sódio para aves de corte da linhagem Colonial criadas em semiconfinamento ${ }^{1}$
}

\author{
Sandra Regina Freitas Pinheiro², Nilva Kazue Sakomura ${ }^{3}$, Iris Mayumi Kawauchi², Melina \\ Aparecida Bonato ${ }^{2}$, Juliano César de Paula Dorigam ${ }^{4}$, João Batista Kochenborger \\ Fernandes $^{5}$
}

\footnotetext{
1 Projeto financiado pelo CNPq.

2 Pós-graduação em Zootecnia - FCAV - UNESP/Jaboticabal.

${ }^{3}$ Departamento de Zootecnia - FCAV - UNESP/Jaboticabal.

${ }^{4}$ Graduação em Zootecnia - FCAV-UNESP/Jaboticabal.

${ }^{5}$ Caunesp - Jaboticabal - SP
}

RESUMO - Objetivou-se determinar níveis de inclusão de cloreto de sódio ( $\mathrm{NaCl}$ ) em rações para aves machos e fêmeas da linhagem Colonial nas fases inicial (1 a 28 dias), de crescimento (28 a 56 dias) e final (56 a 84 dias) criadas em semiconfinamento. Em cada ensaio, 480 aves com idade correspondente à fase de criação foram alojadas em 24 unidades experimentais contendo áreas de abrigo e de pastejo. O delineamento experimental utilizado foi o inteiramente casualizado, em esquema fatorial $4 \times 2$ (níveis de $\mathrm{NaCl}$ e sexos), totalizando oito tratamentos e três repetições de 20 aves. Os níveis de $\mathrm{NaCl}$ avaliados foram: 0,$20 ; 0,40 ; 0,60$ e $0,80 \%$ na fase inicial; 0,$10 ; 0,30 ; 0,50$ e $0,70 \%$ na fase de crescimento e 0,10 ; 0,25; 0,40 e 0,55\% na fase final. Foram avaliados o ganho de peso, o consumo de ração, a ingestão de água, a conversão alimentar, o potencial hidrogeniônico, a pressão parcial de gás carbônico no sangue, a concentração de hematócritos e os teores de sódio e cloro no sangue. Para a fase inicial, o nível recomendado é de 0,53\% de $\mathrm{NaCl}$ na ração para aves de ambos os sexos. Para a fase de crescimento, os níveis de 0,40 e 0,43\% de $\mathrm{NaCl}$, respectivamente, para machos e fêmeas e, para a fase final, de $0,25 \%$ para aves de ambos os sexos, atendem às exigências nutricionais.

Palavras-chave: desempenho, eletrólitos, equilíbrio ácido básico, minerais

\section{Sodium chloride levels for Colonial broiler chickens reared in free-range system}

\begin{abstract}
The objective of this work was to determine inclusion levels of sodium chloride $(\mathrm{NaCl})$ in diets for male and female Colonial strain birds in the starter (from one to 28 days of age), growing (from 28 to 56 days of age) and finisher (from 56 to 84 days of age) phases reared in free-range system. In each trial, 480 birds at age corresponding to the rearing phase were housed in 24 experimental units containing areas of shelter and pasture. The experimental design used was a completely randomized in a $4 \times 2$ factorial arrangement ( $\mathrm{NaCl}$ levels $\times$ sex), totaling eight treatments and three replications of 20 birds. Levels of $\mathrm{NaCl}$ evaluated were: $0.20,0.40,0.60$ and $0.80 \%$ in the starter phase; $0.10,0.30,0.50$ and $0.70 \%$ in the growing phase and $0.10,0.25,0.40$ and $0.55 \%$ in the finisher phase. It was evaluated weight gain, feed intake, water intake, feed conversion, $\mathrm{pH}$, partial pressure of carbon dioxide in the blood, hematocrit concentration and sodium and chlorine blood levels. For the starter phase it is recommended $0.53 \%$ of $\mathrm{NaCl}$ level in diet for birds of both sexes. For the growing phase, the levels were 0.40 and $0.43 \%$ of $\mathrm{NaCl}$, respectively, for males and females, and for the finisher phase, the level of $0.25 \%$ for birds of both sexes meets the nutritional requirements.
\end{abstract}

Key Words: acid-base balance, electrolyte, minerals, performance

\section{Introdução}

Devido às mudanças no padrão de consumo, a criação de aves tipo caipira para produção de ovos e carne é uma atividade promissora, pois uma fatia do mercado consumidor está interessada em adquirir produtos com características organolépticas diferenciadas. Apesar de a demanda por esses produtos ter crescido, as exigências nutricionais das aves dessas linhagens são pouco estudadas e o seu programa alimentar precisa ser estabelecido, para o balanceamento das rações, a fim de obter a máxima eficiência de produção.

O sódio ( $\mathrm{Na}$ ) e o cloro $(\mathrm{Cl})$ são macrominerais essenciais ao metabolismo animal e são facilmente suplementados nas rações sob a forma de cloreto de sódio $(\mathrm{NaCl})$, servindo 
como condimento, que pode melhorar a palatabilidade da ração e, também, como fonte de nutrientes, por conter 39,74\% de Na e 60,23\% de Cl (Maynard \& Loosli, 1974; Borges et al., 1998). Como elementos essenciais, exercem funções na manutenção da pressão osmótica, no equilíbrio ácido básico, no controle da passagem de nutrientes para as células, e no metabolismo de água. A deficiência de qualquer um destes elementos resulta em perda de apetite e atraso no crescimento (Maynard \& Loosli, 1974).

A homeostase dos fluidos corporais está relacionada com a ingestão, retenção e excreção de $\mathrm{Na}^{+}$(Macari et al., 2002). Para manutenção da homeostase orgânica a ingestão desse íon precisa ser adequada.

Rações com altos teores de $\mathrm{Cl}^{-}$diminuem o $\mathrm{pH}$ sanguíneo em frangos, prejudicando o seu crescimento (Borges et al., 2003). Entretanto, a deficiência afeta negativamente o crescimento, causando distúrbios nervosos.

Estudando o desempenho de frangos de corte de $1 \mathrm{a}$ 21 dias, alimentados com níveis de $\mathrm{NaCl}$, Butolo et al. (1995) verificaram melhora na conversão alimentar com $0,55 \%$ de $\mathrm{NaCl}$.

Borges et al. (1998) constataram que para as fases inicial e crescimento, não houve efeito dos níveis de $\mathrm{NaCl}$ avaliados, sugerindo que $0,30 \%$ atende as exigências nas duas fases. Para o período total de criação, o nível de $0,45 \%$ de $\mathrm{NaCl}$ atende ao máximo desempenho das aves.

Ortiz \& Ortuño (1999), avaliando níveis de $\mathrm{NaCl}$ nas rações, observaram que $0,60 \% \mathrm{NaCl}$ melhorou o ganho de peso e a conversão alimentar de frangos de corte de 1 a 49 dias.

Este trabalho foi desenvolvido para determinar os níveis de cloreto de sódio para aves machos e fêmeas da linhagem Colonial, criadas em semiconfinamento nas fases inicial (1 a 28 dias), crescimento (28 a 56 dias) e final (56 a 84 dias de idade).

\section{Material e Métodos}

Foram realizados três ensaios no Setor de Avicultura do Departamento de Zootecnia da Faculdade de Ciências Agrárias e Veterinárias - FCAV/UNESP, Câmpus de Jaboticabal, São Paulo, no período de 7 de janeiro a 31 de março de 2008, para determinar os níveis nutricionais de cloreto de sódio $(\mathrm{NaCl})$ para aves da linhagem Colonial de ambos os sexos, criadas em semiconfinamento nas fases inicial (1 a 28 dias), de crescimento (28 a 56 dias) e final (56 a 84 dias). As aves foram sexadas e vacinadas no incubatório contra as doenças de Marek e Bouba Aviária. No primeiro dia, foram vacinadas contra coccidiose no $5 \underline{0}$ dia, contra gumboro no $12^{\circ} \stackrel{o}{d i a}$, contra Newcastle no $18^{\circ} \underline{o}$ dia, contra gumboro (segunda dose) e, finalmente, contra Newcastle (segunda dose) no 28o dia.

Em cada ensaio, foram utilizadas 480 aves ( 240 machos e 240 fêmeas), distribuídas em delineamento experimental inteiramente casualizado, com oito tratamentos, em esquema fatorial $4 \times 2$ (níveis de cloreto de sódio e sexos) e três repetições de 20 aves por unidade experimental. Os lotes reservas de aves para serem utilizadas nas fases de crescimento e final foram alojados em galpão convencional até o $28^{0}$ e $56^{0}$ dia. As instalações experimentais consistiram de 24 piquetes, dispondo de um abrigo $\left(3,13 \mathrm{~m}^{2}\right)$ e área de pastejo $\left(72,87 \mathrm{~m}^{2}\right)$. Os abrigos possuíam as laterais teladas, providas de cortinas e cobertura de telhas de cimento amianto, com piso forrado com cama de casca de arroz. Cada abrigo foi equipado com um comedouro tubular, bebedouro pendular e lâmpadas de aquecimento infravermelho. A área de pastejo, cercada por tela galvanizada, possuía predominantemente gramíneas do gênero Paspalum. Na fase inicial, as aves com 1 dia de idade foram alojadas nos piquetes e permaneceram limitadas ao abrigo até o $28^{0}$ dia. Nas fases subsequentes, tiveram acesso à área de pastejo e foram soltas diariamente às $8 \mathrm{~h}$, e recolhidas para o abrigo às $18 \mathrm{~h}$. As aves receberam ração e água à vontade e foram criadas somente com luz natural. Diariamente, foram anotadas as temperaturas de máxima e mínima e a umidade relativa do ar no interior das instalações

Para cada fase, foram formuladas rações basais (Tabela 1), compostas principalmente de milho e farelo de soja, considerando as exigências nutricionais de energia metabolizável, proteína bruta, aminoácidos (lisina e metionina + cistina), fósforo disponível e cálcio, conforme pesquisas realizadas na FCAV/Unesp, Jaboticabal. Os demais aminoácidos seguiram as relações aminoacídicas preconizadas por Rostagno et al. (2005).

As rações basais foram suplementadas com cloreto de sódio, resultando em rações isonutritivas, exceto para os níveis de sódio e de cloro. Os níveis de cloreto de sódio avaliados foram: 0,$20 ; 0,40 ; 0,60$ e $0,80 \%$ na fase inicial; 0,$10 ; 0,30 ; 0,50$ e $0,70 \%$ na fase de crescimento e 0,$10 ; 0,25$; 0,40 e $0,55 \%$ na fase final. Os níveis de cloreto de sódio foram ajustados às rações por meio de substituição do material inerte.

As variáveis avaliadas foram: ganho de peso (g/ave), consumo de ração (g/ave), conversão alimentar (g ração consumida/g de ganho de peso), ingestão de água (mL/ave/dia), potencial hidrogeniônico, pressão parcial de dióxido de carbono (mmHg) no sangue, concentração de hematócrito (\%) e níveis de $\mathrm{Na}^{+}(\mathrm{mmol} / \mathrm{L})$ e $\mathrm{Cl}^{-}(\mathrm{mEq} / \mathrm{L})$ no sangue. 
Tabela 1 - Composições das rações experimentais para as fases inicial (1 a 28 dias), de crescimento (28 a 56 dias) e final (56 a 84 dias)

\begin{tabular}{|c|c|c|c|}
\hline \multirow[t]{2}{*}{ Ingrediente } & \multicolumn{3}{|c|}{ Fase } \\
\hline & 1 a 28 dias & 28 a 56 dias & 56 a 84 dias \\
\hline Milho & 63,036 & 64,182 & 73,015 \\
\hline Óleo de soja & 0,340 & 1,440 & 1,321 \\
\hline Fosfato bicálcico & 2,057 & 1,322 & 1,222 \\
\hline Calcário & 0,911 & 1,209 & 0,809 \\
\hline Suplemento mineral ${ }^{1}$ & 0,100 & 0,100 & 0,100 \\
\hline Suplemento vitamínico ${ }^{2}$ & 0,100 & 0,100 & 0,100 \\
\hline Cloreto de colina $70 \%$ & 0,070 & 0,050 & 0,050 \\
\hline Sal comum & 0,200 & 0,100 & 0,100 \\
\hline Inerte $^{3}$ & 0,698 & 0,600 & 0,600 \\
\hline \multicolumn{4}{|l|}{ Composição nutricional calculada } \\
\hline Sódio (\%) & 0,0985 & 0,0587 & 0,0588 \\
\hline Potássio (\%) & 0,7664 & 0,7399 & 0,6168 \\
\hline Cloro $(\%)$ & 0,1668 & 0,107 & 0,107 \\
\hline Metionina + cistina digestível (\%) & 0,710 & 0,716 & 0,597 \\
\hline Lisina digestível (\%) & 1,041 & 1,006 & 0,760 \\
\hline Treonina digestível (\%) & 0,676 & 0,654 & 0,551 \\
\hline Arginina digestível (\%) & 1,258 & 1,210 & 0,984 \\
\hline Triptofano digestível (\%) & 0,218 & 0,210 & 0,170 \\
\hline Valina digestível (\%) & 0,842 & 0,815 & 0,690 \\
\hline
\end{tabular}

Para determinação da ingestão de água, utilizou-se galão com capacidade máxima de $5 \mathrm{~L}$ acoplado ao bebedouro pendular localizado dentro de cada unidade experimental. A medição foi realizada entre o $15^{\circ}$ e o $21^{\text {o }}$ dia de cada ensaio, com a utilização de provetas com capacidade máxima de 1.000 e $2.000 \mathrm{~mL}$, registrando-se as sobras de água do bebedouro mais a do galão. O cálculo foi feito pela diferença entre a quantidade fornecida e as sobras, dividido pelo número de aves da parcela, por dia, descontando-se a mortalidade.

As análises dos parâmetros sanguíneos, do potencial hidrogeniônico, da pressão parcial de dióxido de carbono, sódio, cloro e da concentração de hematócrito foram realizadas no $22^{0}$ dia de cada ensaio. O potencial hidrogeniônico, a pressão parcial de dióxido de carbono e a concentração de hematócrito foram determinados imediatamente após a coleta. Para isso, foram retiradas alíquotas de $1 \mathrm{~mL}$ de sangue de cada ave, escolhidas aleatoriamente (três aves por parcela), na veia jugular, utilizando-se seringa esterilizada e com anticoagulante (heparina). Utilizou-se o analisador de gases sanguíneo da marca i-STAT Portable Clinical Analyzer, provido de cartucho, acoplado à impressora, a qual forneceu os resultados.
Para as análises dos níveis de $\mathrm{Na}^{+}$e $\mathrm{Cl}^{-}$no soro, foram colhidas amostras de $2 \mathrm{~mL}$ de sangue, nas mesmas aves, na veia jugular, utilizando-se seringa esterilizada e sem anticoagulante. As amostras foram transferidas para tubos de ensaio, centrifugadas por oito minutos, a 3.000 rpm e, após a separação do soro, foram imediatamente congeladas até as análises laboratoriais. O nível de $\mathrm{Na}^{+}$ foi determinado pelo método seletor de íons ISELAB e o do $\mathrm{Cl}^{-}$por espectrofotômetro com o uso de reagentes Labtest.

Os dados foram submetidos às análises de variância e os tratamentos desdobrados em regressão polinomial. As estimativas dos níveis ótimos de cloreto de sódio foram feitas pelos modelos Linear Response Plateau (LRP) e/ou quadrático e, quando possível o ajuste simultâneo de ambos os modelos, esse procedimento foi adotado, conforme descrito por Sakomura \& Rostagno (2007). Para aquelas variáveis cujos efeitos dos níveis de $\mathrm{NaCl}$ foram detectados pela análise de variância, mas não foi possível ajustar nenhum dos modelos de regressão propostos, utilizou-se o teste Duncan a 5\% de probabilidade para comparação das médias. As análises estatísticas foram realizadas utilizando-se o programa computacional SAS 9.1 (2009). 


\section{Resultados e Discussão}

As médias de temperatura máxima e mínima foram de 30 e $22^{\circ} \mathrm{C}$, respectivamente, e a média da umidade do ar máxima foi de $90 \%$ e a mínima de $52 \%$. Na fase de 1 a 28 dias de idade, os níveis de $\mathrm{NaCl}$ das rações influenciaram $(\mathrm{P}<0,05)$ o consumo de ração, a ingestão de água, o ganho de peso, a concentração de hematócritos e o teor de sódio sanguíneo (Tabela 2).

O sexo, por sua vez, teve efeito $(\mathrm{P}<0,05)$ no consumo de ração, na ingestão de água, na conversão alimentar, no ganho de peso e na concentração de hematócritos no sangue. Ao ser analisada a interação entre níveis de $\mathrm{NaCl}$ e sexo para a concentração de hematócritos, verificou-se comportamento diferenciado entre machos e fêmeas nos níveis estudados.

Embora os níveis de cloreto de sódio das rações tenham influenciado $(\mathrm{P}<0,05)$ o consumo de ração, nenhum dos modelos estudados ajustou-se aos resultados. Pelo teste de Duncan, foi possível observar que as aves que receberam os níveis de 0,40 a $0,80 \%$ de cloreto de sódio apresentaram maior consumo de ração em comparação àquelas que receberam 0,20\%. Esse resultado difere daqueles encontrados por (Butolo et al., 1995; Borges et al., 1998;
Viana, 2000), que não encontraram efeito no consumo de ração devido aos níveis de cloreto de sódio avaliados.

A ingestão de água pelas aves aumentou $(\mathrm{P}<0,01)$ com o acréscimo de cloreto de sódio na ração. Ao ser ajustado pelo modelo LRP, o nível estimado foi de $0,582 \%$ de $\mathrm{NaCl}$ (Tabela 3). A resposta primária da ave ao excesso de $\mathrm{Na}^{+}$no plasma é a sede, que estimula maior ingestão de água e diminui proporcionalmente a concentração de $\mathrm{Na}^{+}$ plasmático (Macari et al., 2002). Borges et al. (1998) relataram que outros fatores, como as temperaturas da água e do ambiente podem interferir na ingestão de água, dificultando o estabelecimento do valor exato que o aumento do nível de sal na ração provoca na ingestão e suas consequências.

Conforme os níveis de cloreto de sódio na ração aumentaram, houve aumento $(\mathrm{P}<0,01)$ do ganho de peso das aves e isso pode ser devido ao aumento no consumo de ração com os níveis de cloreto de sódio avaliados. Os resultados foram ajustados pelos modelos linear, quadrático e LRP. A estimativa do nível ótimo de cloreto de sódio obtida pelo modelo quadrático foi de $0,648 \%$ e, pelo modelo LRP, de $0,458 \%$. No entanto, pelo método descrito por Sakomura \& Rostagno (2007), estimou-se que o nível de 0,528\% de cloreto de sódio seria o mais adequado (Tabela 3). Trabalhando com frangos de corte de 1 a 49 dias

Tabela 2 - Desempenho das aves da linhagem Colonial no período de 1 a 28 dias alimentadas com rações formuladas com diversos níveis de cloreto de sódio

\begin{tabular}{|c|c|c|c|c|c|c|c|c|c|c|}
\hline & & Probabi & lidade & & Níve & le cloreto & de sódio & & Média & CV (\%) \\
\hline & $\mathrm{NaCl}$ & Sexo & $\mathrm{NaCl} *$ Sexo & Sexo & 0,20 & 0,40 & 0,60 & 0,80 & & \\
\hline Consumo de ração (g/ave) & 0,0359 & 0,0013 & 0,0648 & $\begin{array}{l}\text { Machos } \\
\text { Fêmeas } \\
\text { Média }\end{array}$ & $\begin{array}{c}1015 \\
1017 \\
1016 \mathrm{~B}\end{array}$ & $\begin{array}{c}1135 \\
1027 \\
1081 \mathrm{~A}\end{array}$ & $\begin{array}{c}1137 \\
1082 \\
1109 \mathrm{~A}\end{array}$ & $\begin{array}{c}1173 \\
1005 \\
1089 \mathrm{~A}\end{array}$ & $\begin{array}{l}1115 \\
1033\end{array}$ & 4,85 \\
\hline Ingestão de água (mL/ave/dia) & 0,0001 & 0,0024 & 0,1428 & $\begin{array}{l}\text { Machos } \\
\text { Fêmeas } \\
\text { Média }\end{array}$ & $\begin{array}{l}110,47 \\
102,94 \\
106,70\end{array}$ & $\begin{array}{l}119,80 \\
116,57 \\
118,18\end{array}$ & $\begin{array}{l}127,43 \\
119,58 \\
123,50\end{array}$ & $\begin{array}{l}144,71 \\
122,86 \\
133,78\end{array}$ & $\begin{array}{l}125,60 \\
115,49\end{array}$ & 5,70 \\
\hline Conversão alimentar (g/g) & 0,7509 & 0,0172 & 0,8769 & $\begin{array}{l}\text { Machos } \\
\text { Fêmeas } \\
\text { Média }\end{array}$ & $\begin{array}{l}1,925 \\
1,994 \\
1,960\end{array}$ & $\begin{array}{l}1,933 \\
1,975 \\
1,954\end{array}$ & $\begin{array}{l}1,928 \\
1,963 \\
1,946\end{array}$ & $\begin{array}{l}1,892 \\
1,967 \\
1,929\end{array}$ & $\begin{array}{l}1,919 \\
1,975\end{array}$ & 2,62 \\
\hline Ganho de peso (g/ave) & 0,0004 & 0,0001 & 0,0634 & $\begin{array}{l}\text { Machos } \\
\text { Fêmeas } \\
\text { Média }\end{array}$ & $\begin{array}{l}527 \\
481 \\
504\end{array}$ & $\begin{array}{l}587 \\
520 \\
554\end{array}$ & $\begin{array}{l}590 \\
551 \\
570\end{array}$ & $\begin{array}{l}620 \\
511 \\
566\end{array}$ & $\begin{array}{l}581 \\
516\end{array}$ & 4,09 \\
\hline Potencial hidrogeniônico & 0,9638 & 0,9890 & 0,4701 & $\begin{array}{l}\text { Machos } \\
\text { Fêmeas } \\
\text { Média }\end{array}$ & $\begin{array}{l}7,31 \\
7,27 \\
7,29\end{array}$ & $\begin{array}{l}7,28 \\
7,32 \\
7,30\end{array}$ & $\begin{array}{l}7,30 \\
7,31 \\
7,31\end{array}$ & $\begin{array}{l}7,31 \\
7,30 \\
7,31\end{array}$ & $\begin{array}{l}7,30 \\
7,30\end{array}$ & 0,63 \\
\hline $\begin{array}{l}\text { Pressão parcial de gás } \\
\text { carbônico }(\mathrm{mmHg})\end{array}$ & 0,8200 & 0,4868 & 0,6772 & $\begin{array}{l}\text { Machos } \\
\text { Fêmeas } \\
\text { Média }\end{array}$ & $\begin{array}{l}43,05 \\
45,79 \\
44,42\end{array}$ & $\begin{array}{l}47,30 \\
42,41 \\
44,85\end{array}$ & $\begin{array}{l}47,80 \\
43,69 \\
45,74\end{array}$ & $\begin{array}{l}42,88 \\
42,21 \\
42,54\end{array}$ & $\begin{array}{l}45,26 \\
43,52\end{array}$ & 13,43 \\
\hline Concentração de hematócritos (\%) & 0,0013 & 0,0359 & 0,0002 & $\begin{array}{l}\text { Machos } \\
\text { Fêmeas } \\
\text { Média }\end{array}$ & $\begin{array}{l}21,89 \\
20,67 \\
21,28\end{array}$ & $\begin{array}{l}18,41 \\
19,44 \\
18,93\end{array}$ & $\begin{array}{l}20,44 \\
19,78 \\
20,11\end{array}$ & $\begin{array}{l}17,72 \\
21,67 \\
19,69\end{array}$ & $\begin{array}{l}19,62 \\
20,39\end{array}$ & 4,12 \\
\hline Sódio no sangue (mmol/L) & 0,0201 & 0,8396 & 0,9591 & $\begin{array}{l}\text { Machos } \\
\text { Fêmeas } \\
\text { Média }\end{array}$ & $\begin{array}{l}139,00 \\
139,89 \\
139,44\end{array}$ & $\begin{array}{l}136,75 \\
137,00 \\
136,87\end{array}$ & $\begin{array}{l}136,83 \\
136,50 \\
136,67\end{array}$ & $\begin{array}{l}136,67 \\
136,55 \\
136,61\end{array}$ & $\begin{array}{l}137,31 \\
137,49\end{array}$ & 1,51 \\
\hline Cloro no sangue $(\mathrm{mEq} / \mathrm{L})$ & 0,2953 & 0,2465 & 0,1612 & $\begin{array}{l}\text { Machos } \\
\text { Fêmeas } \\
\text { Média }\end{array}$ & $\begin{array}{l}110,78 \\
108,05 \\
109,42\end{array}$ & $\begin{array}{l}106,61 \\
110,11 \\
108,36\end{array}$ & $\begin{array}{l}108,28 \\
112,28 \\
110,28\end{array}$ & $\begin{array}{l}111,11 \\
111,67 \\
111,39\end{array}$ & $\begin{array}{l}109,19 \\
110,53\end{array}$ & 2,47 \\
\hline
\end{tabular}

Médias seguidas de letras iguais nas linhas não diferem $(\mathrm{P}>0,05)$ pelo teste de Duncan. $\mathrm{CV}=$ coeficiente de variação; $\mathrm{NaCl}=$ cloreto de sódio. 
Tabela 3 - Equações ajustadas para os níveis de cloreto de sódio e coeficientes de determinação para aves da linhagem Colonial na fase inicial

\begin{tabular}{|c|c|c|c|}
\hline Modelo & Variável/Equação & $\mathrm{NNaCl}(\%)$ & $\mathrm{R}^{2}$ \\
\hline \multicolumn{4}{|c|}{ Ingestão de água (mL/ave/dia) } \\
\hline Linear & $\mathrm{IA}=98,905+43,280 \mathrm{NaCl}$ & & 0,98 \\
\hline LRP & $\mathrm{IA}=128,60-57,4038(0,5822-\mathrm{NaCl})$ & 0,582 & 0,86 \\
\hline \multicolumn{4}{|c|}{ Ganho de peso (g/ave) } \\
\hline Linear & $\mathrm{GP}=498,37+100,407 \mathrm{NaCl}$ & & 0,73 \\
\hline LRP & $\mathrm{GP}=568,10-247,20(0,458-\mathrm{NaCl})$ & 0,458 & 0,99 \\
\hline Quadrático & $\mathrm{GP}=430,427+440,118 \mathrm{NaCl}-339,711 \mathrm{NaCl}^{2}$ & 0,648 & 0,99 \\
\hline Quadrático + LRP & $\left(-440,12+\left(440,12^{2}-4 \times(339,71 \times(430,43-568,10))\right)^{1 / 2} /(2 x-339,71)\right.$ & 0,528 & - \\
\hline Linear & $\begin{array}{l}\text { Concentração de hematócritos (\%) - Machos } \\
\text { Hct }=22,235-5,235 \mathrm{NaCl}\end{array}$ & & 0,95 \\
\hline Quadrático & $\begin{array}{l}\text { Concentração de hematócritos (\%) - Fêmeas } \\
\text { Hct }=23,444-17,778 \mathrm{NaCl}+19,444 \mathrm{NaCl}^{2}\end{array}$ & 0,457 & 0,53 \\
\hline \multicolumn{4}{|c|}{ Sódio sanguíneo (mmol/L) } \\
\hline Linear & $\mathrm{Na}=139,576-4,354 \mathrm{NaCl}$ & & 0,67 \\
\hline LRP & $\mathrm{Na}=136,60-12,847(\mathrm{Nacl}-0,4184)$ & 0,418 & 0,99 \\
\hline Quadrático & $\mathrm{Na}=142,7194-20,0697 \mathrm{NaCl}+15,715 \mathrm{NaCl}^{2}$ & 0,638 & 0,96 \\
\hline Quadrático + LRP & $\left(20,07-\left(20,07^{2}-4 \times(15,71 \times(142,72-136,60))\right)^{1 / 2} /(2 \times 15,71)\right.$ & 0,503 & - \\
\hline
\end{tabular}

de idade, Ortiz \& Ortuño (1999) também observaram aumento no ganho de peso das aves com níveis de 0,60 e 0,80\% de cloreto de sódio nas rações. Entretanto, Butolo et al. (1995) não encontraram efeito sobre o ganho de peso dos frangos de corte de 1 a 21 dias, e estimaram o nível de 0,55\% de cloreto de sódio na ração.

O desdobramento da interação entre os níveis de cloreto de sódio e sexo aos resultados da concentração de hematócritos (Hct) apresentou ajuste aos dados dos machos com o modelo linear. Dessa forma, à medida que os níveis de cloreto de sódio aumentaram nas rações, a concentração de hematócrito no sangue decresceu. Os resultados das fêmeas apresentaram comportamento semelhante ao dos machos e foram ajustados pela equação quadrática que estimou o nível de $0,457 \%$ de cloreto de sódio que reduziu a concentração de hematócrito no sangue (Tabela 3). Esses resultados estão de acordo com os descritos por Lott et al. (1992), que, em pesquisa com frangos de corte dos 36 aos 39 dias de idade, verificaram redução na taxa de hematócrito à medida que níveis de sódio foram acrescidos à água de bebida. Devido aos acréscimos na ingestão de cloreto de sódio pelas aves que receberam maiores suplementações nas rações, os processos metabólicos para manterem a homeostase orgânica foram acionados, resultando em maior ingestão de água pelas aves. Esse fato pode ter favorecido a hemodiluição, que, por sua vez, propiciou menores valores de hematócrito no sangue. Quando ocorre alteração na pressão osmótica do sangue, as hemácias podem se romper, devido à menor concentração de íons na solução (hipotônica) plasmática, diminuindo a concentração de células vermelhas circulantes (Macari et al., 2002).

O teor de sódio sanguíneo $\left(\mathrm{Na}^{+}\right)$foi ajustado pelos modelos linear, LRP e quadrático, sendo verificado que os acréscimos nos níveis de cloreto de sódio nas rações resultaram em menores teores $\mathrm{Na}^{+}$no sangue. O modelo LRP estimou o nível de 0,418\% de cloreto de sódio e a equação quadrática estimou o nível de $0,638 \%$ como o ponto em que ocorrem menores valores para o $\mathrm{Na}^{+}$ sanguíneo. Pela associação dos dois modelos, obtêm-se o nível de 0,503\% de cloreto de sódio na ração. Essa redução do teor de $\mathrm{Na}^{+}$no sangue pode estar relacionada à maior ingestão de água, que acarretou na hemodiluição com os crescentes níveis de cloreto de sódio das rações. A regulação do conteúdo de sódio do plasma e, portanto a osmolalidade do plasma e o volume intracelular, ocorre por mudanças no equilíbrio hídrico. As oscilações na ingestão diária são seguidas de adaptações na excreção urinária (Macari et al., 2002).

Para a fase de crescimento, 28 a 56 dias, obtiveram-se as médias de temperatura máxima e mínima de 32 e $20^{\circ} \mathrm{C}$, respectivamente, enquanto, as médias de umidade relativa do ar foram de $86 \%$ para o valor máximo e de $40 \%$ para o mínimo.

Os níveis de cloreto de sódio das rações influenciaram $(\mathrm{P}<0,01)$ o consumo de ração, a ingestão de água, a conversão alimentar, o ganho de peso, o nível de sódio e cloro no sangue. O sexo também teve efeito $(\mathrm{P}<0,01)$ no consumo de ração, na ingestão de água, na conversão alimentar, no ganho de peso, no potencial hidrogeniônico 
Tabela 4 - Desempenho das aves da linhagem Colonial no período de 28 a 56 dias alimentadas com rações formuladas com diversos níveis de cloreto de sódio

\begin{tabular}{|c|c|c|c|c|c|c|c|c|c|c|}
\hline & \multicolumn{3}{|c|}{ Probabilidade } & \multicolumn{5}{|c|}{ Nível de cloreto de sódio (\%) } & \multirow[t]{2}{*}{ Média } & \multirow[t]{2}{*}{ CV (\%) } \\
\hline & $\mathrm{NaCl}$ & Sexo & $\mathrm{NaCl} *$ Sexo & Sexo & 0,10 & 0,30 & 0,50 & 0,70 & & \\
\hline Consumo de ração (g/ave) & 0,0036 & 0,0001 & 0,4387 & $\begin{array}{l}\text { Machos } \\
\text { Fêmeas } \\
\text { Média }\end{array}$ & $\begin{array}{c}2992 \\
2560 \\
2776 \mathrm{~B}\end{array}$ & $\begin{array}{c}3234 \\
2733 \\
2983 \mathrm{~A}\end{array}$ & $\begin{array}{c}3281 \\
2720 \\
3001 \mathrm{~A}\end{array}$ & $\begin{array}{c}3334 \\
2703 \\
3019 A\end{array}$ & $\begin{array}{l}3210 \\
2679\end{array}$ & 3,61 \\
\hline Ingestão de água (mL/ave/dia) & 0,0007 & 0,0002 & 0,8437 & $\begin{array}{l}\text { Machos } \\
\text { Fêmeas } \\
\text { Média }\end{array}$ & $\begin{array}{l}163,62 \\
142,62 \\
153,12\end{array}$ & $\begin{array}{l}175,01 \\
148,26 \\
161,64\end{array}$ & $\begin{array}{l}188,92 \\
157,94 \\
173,43\end{array}$ & $\begin{array}{l}213,97 \\
178,17 \\
196,07\end{array}$ & $\begin{array}{l}185,38 \\
156,75\end{array}$ & 8,61 \\
\hline Conversão alimentar (g/g) & 0,0001 & 0,0001 & 0,3832 & $\begin{array}{l}\text { Machos } \\
\text { Fêmeas } \\
\text { Média }\end{array}$ & $\begin{array}{l}2,933 \\
3,113 \\
3,023\end{array}$ & $\begin{array}{l}2,564 \\
2,842 \\
2,703\end{array}$ & $\begin{array}{l}2,590 \\
2,766 \\
2,678\end{array}$ & $\begin{array}{l}2,595 \\
2,903 \\
2,749\end{array}$ & $\begin{array}{l}2,671 \\
2,906\end{array}$ & 2,84 \\
\hline Ganho de peso (g/ave) & 0,0001 & 0,0001 & 0,0145 & $\begin{array}{l}\text { Machos } \\
\text { Fêmeas } \\
\text { Média }\end{array}$ & $\begin{array}{c}1021 \\
863 \\
942\end{array}$ & $\begin{array}{c}1261 \\
962 \\
1111\end{array}$ & $\begin{array}{c}1267 \\
983 \\
1125\end{array}$ & $\begin{array}{c}1286 \\
985 \\
1135\end{array}$ & $\begin{array}{c}1209 \\
948\end{array}$ & 3,56 \\
\hline Potencial hidrogeniônico & 0,2455 & 0,0331 & 0,3808 & $\begin{array}{l}\text { Machos } \\
\text { Fêmeas } \\
\text { Média }\end{array}$ & $\begin{array}{l}7,41 \\
7,35 \\
7,38\end{array}$ & $\begin{array}{l}7,41 \\
7,35 \\
7,38\end{array}$ & $\begin{array}{l}7,41 \\
7,41 \\
7,41\end{array}$ & $\begin{array}{l}7,39 \\
7,37 \\
7,38\end{array}$ & $\begin{array}{l}7,40 \\
7,37\end{array}$ & 0,42 \\
\hline $\begin{array}{l}\text { Pressão parcial de gás } \\
\text { carbônico }(\mathrm{mmHg})\end{array}$ & 0,6596 & 0,4021 & 0,5277 & $\begin{array}{l}\text { Machos } \\
\text { Fêmeas } \\
\text { Média }\end{array}$ & $\begin{array}{l}36,18 \\
39,05 \\
37,62\end{array}$ & $\begin{array}{l}33,78 \\
37,61 \\
35,69\end{array}$ & $\begin{array}{l}35,91 \\
34,35 \\
35,13\end{array}$ & $\begin{array}{l}36,29 \\
36,11 \\
36,20\end{array}$ & $\begin{array}{l}35,54 \\
36,78\end{array}$ & 9,78 \\
\hline Concentração de hematócritos (\%) & 0,2613 & 0,8923 & 0,7963 & $\begin{array}{l}\text { Machos } \\
\text { Fêmeas } \\
\text { Média }\end{array}$ & $\begin{array}{l}20,89 \\
21,22 \\
21,05\end{array}$ & $\begin{array}{l}19,33 \\
19,67 \\
19,50\end{array}$ & $\begin{array}{l}20,33 \\
19,00 \\
19,67\end{array}$ & $\begin{array}{l}18,94 \\
19,22 \\
19,08\end{array}$ & $\begin{array}{l}19,87 \\
19,78\end{array}$ & 8,73 \\
\hline Sódio no sangue (mmol/L) & 0,0003 & 0,0137 & 0,3686 & $\begin{array}{l}\text { Machos } \\
\text { Fêmeas } \\
\text { Média }\end{array}$ & $\begin{array}{l}138,89 \\
140,44 \\
139,67\end{array}$ & $\begin{array}{l}140,33 \\
141,11 \\
140,72\end{array}$ & $\begin{array}{l}141,67 \\
142,11 \\
141,89\end{array}$ & $\begin{array}{l}140,22 \\
140,46 \\
140,34\end{array}$ & $\begin{array}{l}140,28 \\
141,03\end{array}$ & 0,47 \\
\hline Cloro no sangue $(\mathrm{mEq} / \mathrm{L})$ & 0,015 & 0,1677 & 0,9888 & $\begin{array}{c}\text { Machos } \\
\text { Fêmeas } \\
\text { Média }\end{array}$ & $\begin{array}{l}95,89 \\
96,67 \\
96,28 \\
\end{array}$ & $\begin{array}{l}97,44 \\
98,33 \\
97,89 \\
\end{array}$ & $\begin{array}{l}98,22 \\
98,78 \\
98,50 \\
\end{array}$ & $\begin{array}{l}97,67 \\
98,78 \\
98,22 \\
\end{array}$ & $\begin{array}{l}97,30 \\
98,14\end{array}$ & 1,45 \\
\hline
\end{tabular}

Médias seguidas de letras iguais nas linhas não diferem pelo teste de Duncan $(\mathrm{P}>0,05)$. CV = coeficiente de variação; NaCl = cloreto de sódio.

e no sódio sanguíneo. Houve interação significativa $(\mathrm{P}<0,05)$ dos níveis de cloreto de sódio e do sexo para o ganho de peso (Tabela 4).

Embora o consumo de ração tenha sido influenciado $(\mathrm{P}<0,01)$ pelos níveis de cloreto de sódio, nenhum dos modelos propostos ajustou-se adequadamente, sendo aplicado o teste de Duncan. O menor consumo de ração foi obtido com o nível de $0,10 \%$ de cloreto de sódio. Borges et al. (1998) não encontraram efeito da suplementação de cloreto de sódio nas rações sobre o consumo de ração dos frangos de corte na fase de crescimento.

Houve efeito $(\mathrm{P}<0,01)$ da ingestão de água pelas aves e os resultados foram ajustados pelos modelos linear e LRP. O modelo LRP estimou o nível de 0,291\% de cloreto de sódio, ocorrendo a partir desse nível um platô (Tabela 5). A relação de consumo de água: ração esperada para frangos de corte é de 2:1 e a consequência da maior ingestão de água é o aumento da umidade da cama (Borges et al., 1998). Neste estudo a umidade da cama não dificultou o manejo, mas isso se deve ao fato que as aves criadas em semiconfinamento passam grande parte do tempo nos piquetes, não apresentando o problema nesse sistema de criação.

Para a conversão alimentar, verificou-se influência $(\mathrm{P}<0,01)$ dos níveis de cloreto de sódio, sendo o ajuste obtido pelos modelos linear, LRP e quadrático. A estimativa do modelo LRP foi de $0,293 \%$ de cloreto de sódio na ração e pelo quadrático, o nível estimado foi de $0,486 \%$. A interseção da equação quadrática com o platô do LRP estimou o nível ótimo de $0,327 \%$ de cloreto de sódio para reduzir a conversão alimentar (Tabela 5). Ortiz \& Ortuño (1999) encontraram para frangos de 1 a 49 dias nível maior de cloreto de sódio para otimização da conversão alimentar.

O desdobramento da interação entre os fatores avaliados para o ganho de peso (GP) indicou que os modelos linear, LRP e quadrático ajustaram-se aos resultados dos machos e fêmeas. Considerando os resultados dos machos, as estimativas fornecidas pelos modelos LRP e quadrático indicaram os níveis de 0,313 e $0,544 \%$ de $\mathrm{NaCl}$, respectivamente. Com a associação dos modelos, LRP e quadrático, estimou-se o nível de $0,396 \%$, que corresponde a $0,18 \%$ de sódio e $0,28 \%$ de cloro na ração. O comportamento das respostas do ganho de peso das fêmeas em função dos níveis de cloreto de sódio foi similar ao dos machos. Com base no modelo LRP, a máxima resposta de ganho de peso foi alcançada com o nível estimado em $0,345 \%$ de cloreto de sódio e estabilizou-se a partir de então. Pela equação quadrática, a máxima resposta foi obtida com o nível estimado em 0,559\%. Utilizando-se a primeira intersecção da equação 
Tabela 5 - Equações ajustadas para os níveis de cloreto de sódio e coeficientes de determinação para aves da linhagem Colonial na fase de crescimento

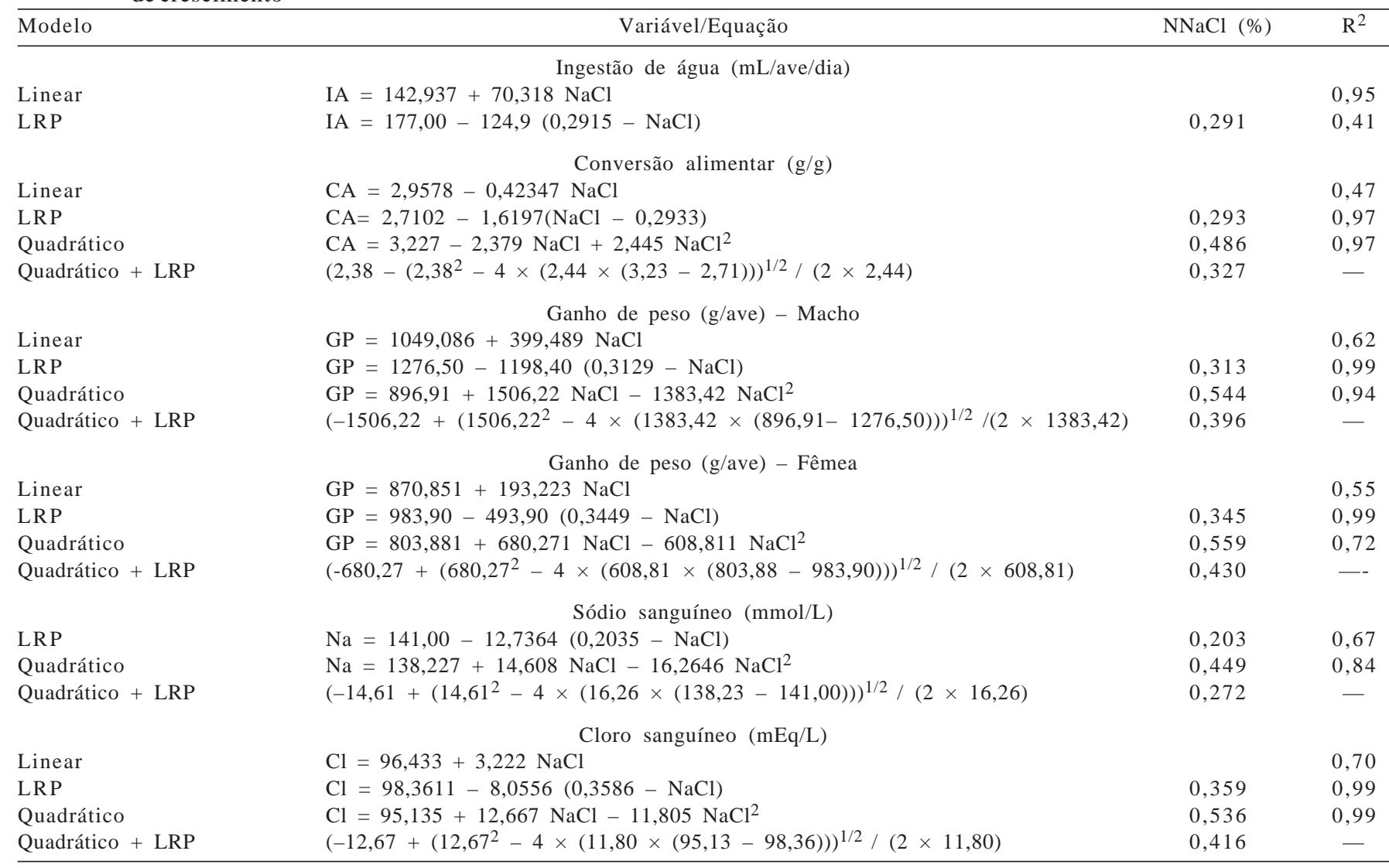

quadrática com o platô do LRP, estimou-se o nível de 0,430\% de cloreto de sódio, correspondendo a 0,19\% de sódio e $0,31 \%$ de cloro na ração (Tabela 5). As diferenças encontradas nas exigências de cloreto de sódio para machos e fêmeas comprovam que os machos possuem maior eficiência para ganho de peso que fêmeas, pois, com níveis menores do nutriente, é capaz de apresentar melhores resultados (Tabelas 4 e 5). Murakami et al. (2001), estudando as exigências de sódio e cloro, separadamente, recomendaram os níveis de $0,12 \%$ de sódio e $0,20 \%$ de cloro para maximização do ganho de peso em frangos de corte em crescimento, níveis inferiores aos encontrados neste experimento.

Avaliando o nível de sódio $\left(\mathrm{Na}^{+}\right)$sanguíneo, constatou-se que os níveis de cloreto de sódio influenciaram $(\mathrm{P}<0,01)$ esta variável. A análise dos modelos aplicados indicou níveis de 0,203 e 0,449\% de cloreto de sódio, respectivamente, para os modelos LRP e quadrático. Contudo, pela associação dos dois modelos, o nível de 0,272\% de cloreto de sódio aumenta o teor de $\mathrm{Na}^{+}$sanguíneo.

Observou-se efeito $(\mathrm{P}<0,05)$ do teor de cloro $\left(\mathrm{Cl}^{-}\right)$ sanguíneo com os diferentes níveis de $\mathrm{NaCl}$ das rações. Pela análise dos resultados, verificou-se que os modelos linear, LRP e quadrático ajustaram-se, sendo estimado 0,359\% (LRP) e 0,536\% (quadrático) de cloreto de sódio na ração que maximizou o nível desse íon no soro. A interseção da equação quadrática com o platô do LRP forneceu o nível de 0,416\% de cloreto de sódio (Tabela 5). O aumento no $\mathrm{Cl}^{-}$sanguíneo deprime a excreção de $\mathrm{H}^{+}$e a reabsorção de $\mathrm{HCO}_{3}{ }^{-}$pelos rins. Isto poderia contribuir com a acidificação do sangue (Borges et al., 2003), todavia nesta fase não houve diferenças significativas no $\mathrm{pH}$ sanguíneo relacionadas aos níveis de cloreto de sódio avaliados.

$\mathrm{Na}$ fase final, 56 a 84 dias de idade, as médias de temperatura máxima e mínima foram 31 e $21^{\circ} \mathrm{C}$, respectivamente, e a média da umidade relativa do ar máxima foi de 84\% e a mínima de 40\%. A análise dos resultados indicou que os níveis de cloreto de sódio das rações influenciaram $(\mathrm{P}<0,05)$ a ingestão de água, o ganho de peso, o pH sanguíneo e o teor de cloro no sangue. No entanto, somente as variáveis de desempenho foram influenciadas $(\mathrm{P}<0,01)$ pelo sexo. A ingestão de água foi a única variável afetada em que se observou efeito da interação entre os níveis de cloreto de sódio e o sexo (Tabela 6).

O desdobramento da interação entre os fatores para a ingestão de água mostrou que os modelos linear e LRP 
ajustaram-se aos resultados das fêmeas. A estimativa obtida pelo LRP foi de $0,248 \%$ de cloreto de sódio na ração, ocorrendo após estabilização na resposta. Para os machos, nenhum dos modelos aplicados ajustou-se aos resultados (Tabela 7). Borges et al. (1999) verificaram que, manipulando as rações com níveis de sódio e cloro, ocorria aumento linear na ingestão de água pelos frangos de corte, e justificaram que o aumento na ingestão de sódio aumenta a resistência osmótica do sangue e atua no controle da ingestão de água pelas aves de forma a satisfazer a sensação de sede.

Embora os níveis de cloreto de sódio tenham influenciado $(\mathrm{P}<0,05)$ o ganho de peso (GP), não foi possível o ajuste adequado dos modelos estudados para essa variável, sendo utilizado o teste Duncan. Verifica-se, pelos resultados, que as aves alimentadas com rações contendo o menor nível de cloreto de sódio $(0,10 \%)$ apresentaram o pior ganho de peso (Tabela 6). Nos níveis subseqüentes, houve melhora com os acréscimos de cloreto de sódio nas rações e estes não diferiram entre si. A melhora observada no ganho de peso no segundo nível $(0,25 \%)$ em relação ao primeiro foi de $13 \%$, correspondendo a $0,12 \%$ de sódio e $0,20 \%$ de cloro na ração. Considerando que as exigências em sódio e cloro diminuem com o avanço na idade das aves, Rostagno et al. (2005) elaboraram equações que permitem estimar os níveis desses nutrientes em função da idade da ave. Pelos cálculos das equações estimaram-se os níveis de $0,15 \%$ de sódio e $0,13 \%$ de cloro para os machos e $0,14 \%$ de sódio e $0,12 \%$ de cloro para as fêmeas.

Tabela 6 - Desempenho de aves da linhagem Colonial no período de 56 a 84 dias alimentadas com rações formuladas com diversos níveis de cloreto de sódio

\begin{tabular}{|c|c|c|c|c|c|c|c|c|c|c|}
\hline & \multicolumn{3}{|c|}{ Probabilidade } & \multicolumn{5}{|c|}{ Nível de cloreto de sódio (\%) } & \multirow[t]{2}{*}{ Média } & \multirow[t]{2}{*}{ CV $(\%$} \\
\hline & $\mathrm{NaCl}$ & Sexo & $\mathrm{NaCl} *$ Sexo & Sexo & 0,10 & 0,25 & 0,40 & 0,55 & & \\
\hline \multirow[t]{3}{*}{ Consumo de ração (g/ave) } & 0,4401 & 0,0001 & 0,5942 & Machos & 4349 & 4514 & 4346 & 4318 & 4382 & 4,06 \\
\hline & & & & Fêmeas & 3272 & 3344 & 3424 & 3279 & 3330 & \\
\hline & & & & Média & 3810 & 3929 & 3885 & 3798 & & \\
\hline \multirow[t]{3}{*}{ Ingestão de água (mL/ave/dia) } & 0,0054 & 0,0001 & 0,0250 & Machos & 309,83 & 317,58 & 328,10 & 312,23 & 316,94 & 4,07 \\
\hline & & & & Fêmeas & 191,01 & 196,14 & 217,67 & 229,28 & 208,53 & \\
\hline & & & & Média & 250,42 & 256,86 & 272,89 & 270,76 & & \\
\hline \multirow[t]{3}{*}{ Conversão alimentar (g/g) } & 0,2151 & 0,0001 & 0,9539 & Machos & 3,819 & 3,654 & 3,727 & 3,674 & 3,718 & 4,38 \\
\hline & & & & Fêmeas & 4,327 & 4,113 & 4,151 & 4,063 & 4,161 & \\
\hline & & & & Média & 4,068 & 3,883 & 3,939 & 3,868 & & \\
\hline \multirow[t]{3}{*}{ Ganho de peso (g/ave) } & 0,0369 & 0,0001 & 0,4455 & Machos & 1057 & 1236 & 1170 & 1176 & 1160 & 4,09 \\
\hline & & & & Fêmeas & 759 & 813 & 824 & 808 & 801 & \\
\hline & & & & Média & $908 \mathrm{~B}$ & $1025 \mathrm{~A}$ & $997 \mathrm{~A}$ & $992 \mathrm{~A}$ & & \\
\hline \multirow[t]{3}{*}{ Potencial hidrogeniônico } & 0,0335 & 0,0776 & 0,1984 & Machos & 7,40 & 7,41 & 7,40 & 7,39 & 7,40 & 6,65 \\
\hline & & & & Fêmeas & 7,41 & 7,37 & 7,40 & 7,34 & 7,38 & \\
\hline & & & & Média & 7,41 & 7,39 & 7,40 & 7,36 & & \\
\hline \multirow{3}{*}{$\begin{array}{l}\text { Pressão parcial de gás } \\
\text { carbônico }(\mathrm{mmHg})\end{array}$} & 0,6323 & 0,2753 & 0,1210 & Machos & 38,88 & 34,97 & 35,72 & 36,03 & 36,40 & 9,26 \\
\hline & & & & Fêmeas & 34,48 & 37,91 & 38,02 & 41,54 & 37,99 & \\
\hline & & & & Média & 36,68 & 36,44 & 36,87 & 38,79 & & \\
\hline \multirow{3}{*}{$\begin{array}{l}\text { Concentração de } \\
\text { hematócritos (\%) }\end{array}$} & 0,9671 & 0,6227 & 0,4576 & Machos & 22,14 & 21,22 & 21,00 & 23,00 & 21,84 & 8,74 \\
\hline & & & & Fêmeas & 22,44 & 22,39 & 22,78 & 21,33 & 22,24 & \\
\hline & & & & Média & 22,29 & 21,80 & 21,89 & 22,17 & & \\
\hline \multirow[t]{3}{*}{ Sódio no sangue (mmol/L) } & 0,2836 & 0,6269 & 0,7429 & Machos & 145,55 & 138,78 & 139,33 & 136,89 & 140,14 & 3,89 \\
\hline & & & & Fêmeas & 140,28 & 139,22 & 140,33 & 136,33 & 139,04 & \\
\hline & & & & Média & 142,92 & 139,00 & 139,83 & 136,61 & & \\
\hline \multirow[t]{3}{*}{ Cloro no sangue $(\mathrm{mEq} / \mathrm{L})$} & 0,0481 & 0,2444 & 0,0586 & Machos & 98,22 & 104,50 & 105,94 & 103,28 & 102,99 & 3,36 \\
\hline & & & & Fêmeas & 101,22 & 106,50 & 99,28 & 98,17 & 101,29 & \\
\hline & & & & Média & $99,72 \mathrm{~B}$ & $105,50 \mathrm{~A}$ & $102,61 \mathrm{AB}$ & $100,72 B$ & & \\
\hline
\end{tabular}

Médias seguidas de letras iguais nas linhas não diferem pelo teste de Duncan $(\mathrm{P}>0,05)$. $\mathrm{CV}=$ coeficiente de variação; $\mathrm{NaCl}=$ cloreto de sódio.

Tabela 7 - Equações ajustadas para os níveis de cloreto de sódio e coeficientes de determinação para aves da linhagem Colonial na fase final

\begin{tabular}{|c|c|c|c|}
\hline Modelo & Variável/Equação & $\mathrm{NNaCl}(\%)$ & $\mathrm{R}^{2}$ \\
\hline $\begin{array}{l}\text { Linear } \\
\text { LRP }^{1}\end{array}$ & $\begin{array}{l}\text { Ingestão de água (mL/ave/dia) }- \text { Fêmea } \\
\mathrm{IA}=178,981+90,9103 \mathrm{NaCl} \\
\mathrm{IA}=214,40-157,80(0,248-\mathrm{NaCl})\end{array}$ & $\overline{0,248}$ & $\begin{array}{l}0,95 \\
0,42\end{array}$ \\
\hline Linear & $\begin{array}{c}\text { pH sanguíneo } \\
\text { pH }=7,4157-0,076 \mathrm{NaCl}\end{array}$ & - & 0,70 \\
\hline
\end{tabular}


O pH sanguíneo reduziu $(\mathrm{P}<0,05)$ com os crescentes níveis de cloreto de sódio das rações e o ajuste dos resultados foi obtido pelo modelo linear decrescente (Tabela 7). Esse resultado era previsto, pois, com o aumento nos níveis de cloreto de sódio das rações, o cloro aumenta mais que o sódio, uma vez que o cloreto de sódio possui cerca $60,23 \%$ de cloro contra 39,74\% de sódio e, como o cloro é um íon de caráter acidogênico, é possível que a elevação dos níveis de $\mathrm{NaCl}$ nas rações tenham propiciado declínio no $\mathrm{pH}$ sanguíneo. Esse fato não resultou em efeitos adversos, pois, de acordo com Macari et al. (2002), o pH do sangue das aves varia sob condições fisiológicas, na faixa de 7,20 a 7,36.

Os níveis de $\mathrm{NaCl}$ avaliados influenciaram $(\mathrm{P}<0,05)$ o teor de cloro $\left(\mathrm{Cl}^{-}\right)$sanguíneo, porém não foi possível o ajuste adequado dos modelos estudados para essa variável. A análise, por meio do teste Duncan, demonstrou que os níveis $(0,25$ e $0,40 \%$ de $\mathrm{NaCl})$ apresentaram maiores valores para o $\mathrm{Cl}^{-}$no sangue. Segundo Borges et al. (2003), o aumento do $\mathrm{Cl}^{-}$sanguíneo pode contribuir para a acidificação do sangue.

\section{Conclusões}

Recomenda-se para aves da linhagem Colonial de ambos os sexos no período de 1 a 28 dias de idade o nível de $0,53 \%$ de cloreto de sódio na ração. Para o período de 28 a 56 dias de idade, os níveis de 0,40 e $0,43 \%$ para machos e fêmeas, respectivamente, e, para fase final ( 56 a 84 dias de idade), o nível é de $0,25 \%$ de $\mathrm{NaCl}$, independentemente do sexo.

\section{Referências}

BORGES, S.A.; ARIKI, J.; JERÔNIMO JUNIOR, R. et al. Níveis de cloreto de sódio em rações para frangos de corte. Arquivo Brasileiro Medicina Veterinária e Zootecnia, v.50, n.5, p.619-624, 1998.

BORGES, S.A.; ARIKI, J.; SANTIN, E. et al. Balanço eletrolítico em dieta pré-inicial de frangos de corte durante o verão. Revista Brasileira de Ciência Avícola, v.1, n.3, p.175-179, 1999.

BORGES, S.A.; MAIORKA, A.; SILVA, A.V.F. Fisiologia do estresse calórico e a utilização de eletrólitos em frangos de corte. Ciência Rural, v.33, n.5, p.975-981, 2003.

BUTOLO, E.A.F.; NOBRE, P.T.C.; LIMA, I.A. Estudo do desempenho de frangos de corte alimentados com diferentes níveis de cloreto de sódio ( $\mathrm{NaCl})$. In: CONFERÊNCIA APINCO DE CIÊNCIA E TECNOLOGIAS AVÍCOLAS APINCO, 1995, Curitiba. Anais... Curitiba: APINCO, 1995. p.51-52.

LOTT, B.D.; WIDEMAN, R.F.; MAY, R.F. The effect of sodium loading on male broilers. Poultry Science, v.71 (suppl.), p.121, 1992. (Abstract).

MACARI, M.; FURLAN, R.L.; GONZALES, E. Fisiologia aviária. Aplicada a frangos de corte. 2.ed. Jaboticabal: FUNEP, 2002. $375 p$.

MAYNARD, L.A.; LOOSLI, J.K. Nutrição animal. 3.ed. Rio de Janeiro: Livraria Freitas Bastos S.A., 1974. p.158-160.

MURAKAMI, A.E.; OVIEDO-RONDÓN, E.O.; MARTINS, E.N. et al. Sodium and chloride requirements of growing broiler chickens (twenty-one to forty-two days of age) fed cornsoybean diets. Poultry Science, v.80, n.3, p.289-294, 2001.

ORTIZ, J.; ORTUÑO, R. Evaluación del comportamiento productivo de pollos parrileros alimentados con diferentes niveles de cloruro de sódio. In: CONGRESSO LATINOAMERICANO DE AVICULTURA, 16., 1999, Lima. Anais... Lima, 1999, p.107-112.

Rostagno, H.S.; ALBINO, L.F.T.; DOnZELE, J.L. Tabelas brasileiras para aves e suínos (composição de alimentos e exigências nutricionais). Viçosa, MG: UFV, 2005. 186p.

SAKOMURA, N.K.; ROSTAGNO, H.S. Métodos de pesquisa em nutrição de monogástricos. Jaboticabal: FUNEP, 2007. 283p.

STATISCAL ANALYSIS SYSTEM - SAS. User's guide: Statistics, Version. 9.1 edition. Cary: SAS Institute Inc., 2009. 20p.

VIANA, R.M. Influência de diferentes níveis de cloreto de sódio ( $\mathrm{NaCl}$ ) em rações de frangos de corte. 2000. 32f. Monografia (Graduação em Agronomia) - Universidade Federal do Amazonas, Manaus. 